\title{
Revealing Hidden \\ Spatial Attributes
}

ANDREAS SAVVIDES - SPYROS SPYROU

- TERESA TOURVAS

University of Cyprus, Department of Architecture 
The premise of the studio, the discovering and mapping of aspects of 'hidden' spatial publicness as a primer for the collaborative design of shared collective space in the public domain, as this is framed by individual addition based on a consensus proposal by students of the first semester, second year students at the Department of Architecture of the University of Cyprus, emanates from a number of readings and references that set the pedagogical framework for this design exercise. One such reference comes from Jane Jacobs' description of the qualities of living in lively cities and she is basing those observations from her personal experience living in Greenwich Village in New York City. Her observation that 'cities were no longer being built as agglomerations of city space and buildings, but rather, as individual buildings,' [1] finds resonance with our pedagogical mandate that quality public collective space, which is often hidden, can be the result of happenstance, but also the result of deliberately executing a collaborative strategy where individual building proposals are also subordinated by the collective design of the space between the buildings.

Another important reference comes from Jan Gehl - a few years after Jacobs' writings - who noted that as we approach the turn of the century and with the majority of the global population becoming increasingly urbanized, great focus needs to be placed the needs of urban dwellers in terms of strengthening the social function of urban spaces as places of increased physical and also social sustainability. This is a view strongly supported as well by Richard Rogers, who in his forward to Jan Gehl's latest edition of 'Cities for People' also notes that cities are places where people 'meet to socialize and to relax, to exchange ideas and to be creative, to work and to trade' [2]. Therefore, in agreement that the urban domain is a strong catalyst for collective pastimes and activities, students are asked to uncover the hidden social dimensions of these places.

Moreover, students are encouraged to address the concept of the city as a compact organism, which sees the integration of nodes and corridors related to urban mobility as a key and viable ingredient to the creation of socially, environmentally, economically and even culturally sustainable city form. However, for this urban compactness to be achieved, the city must offer urban spaces of a significant quantity and of a substantial quality for people to use as the outlet for collective activities juxtaposed to the expected high densities of programs for living and working spaces. These spaces which are often hidden enable compact cities to come to the support of public life and to encourage and accommodate diverse public activities and 
functions that range 'from the quiet and contemplative to the noisy and busy,' while all the time remain respectful of health, safety and the human scale of the individual city dweller.

\section{PROCESS}

The value of public spaces and their social function in cities has been the source of numerous writings. The question posed in our studio is: 'What core design aspects create successful public places, and how do they constitute conscious design processes?' This paper will attempt to address the topic of spatial publicness within a framework of translating observations of the above into design strategies and tools. These aspects have formulated the basis for recent design briefs, tested within an architectural studio context from 2 nd year coursework. The value of Public spaces and their social function in cities that has been the source of numerous writings for well over fifty years now. What are core values that create successful public places, and how do they enter a conscious design process. This paper addresses the topic of spatial publicness and attempts to establish a framework of transferable values. These values have formulated the basis for an ongoing research project tested within the studio context. Examples from early design studios (years 1\&2) will be used as case studies.

\section{METHODOLOGY}

It is thereby important to create a process of incremental transformation that make use of, strengthen, or reconstitutes existing spatial, social and contextual networks. Consequently, a number of tools have been introduced to the methodological approach towards formulating a successful public place [3], so that wherever possible it should:

- Be located where it is easily accessible to and can be easily seen by potential users.

- Clearly convey the fact that it is available for use and is meant to be used.

- Be engaging on both the outside and the inside.

- Be furnished to support frequent and desirable activities.

- Provide a feeling of security and safety to potential users.

- Offer relief from urban stress and enhance the health and wellbeing of its users.

- Be geared to the needs of the user group most likely to use the space.

- Offer an environment that is physiologically comfortable regarding natural lighting and ventilation. 
- Be accessible to disabled people, to the elderly and to children.

- Incorporate components that the users may manipulate or change.

- Allow users the option to care for it through involvement in its design, construction or maintenance.

- Allow use for special events or for temporarily claiming personal spaces within the setting.

- Be easily and economically maintained within the limits of what is normally expected.

- Be designed with attention paid to place as expression of visual art and place as social setting.

\section{SPECIFIC REFERENCES}

1 J. Jacobs (1961). The death and life of great American cities, New York: Random House.W.-K. Chen, Linear Networks and Systems (Book style). Belmont, CA: Wadsworth, 1993, pp. 123-135.

2 J. Gehl (2010). Cities for People, Island Press, Washington, DC.

3 S. Carr, M. Francis, L. G. Rivlin, A. M. Stone (1992). Public Space, Cambridge, Cambridge University Press.

\section{GENERAL REFERENCES}

Ching, F. D. (2014). Architecture: Form, space, and order. John Wiley \& Sons.

Hertzberger, H. (2005). Lessons for students in architecture (Vol. 1). 010 Publishers.

Leach, N. (2005). Rethinking architecture: a reader in cultural theory. Routledge.

Tschumi, B. (1996). Architecture and disjunction. MIT press. Unwin, S. (2003). Analysing architecture. Psychology Press Von Meiss, P. (2013). Elements of architecture: from form to place. Routledge.

\section{ACKNOWLEDGEMENT:}

Our thanks to the following students whose work is featured on this poster:

Andreas Constantinou, Angelos Xenofontos, Antonia Stavrou, Eirini Kleidara, Eleni Tsimara, Georgia Giannakopoulou, Pavlos Sofokleous, Vasiliki Papasoteriou. 


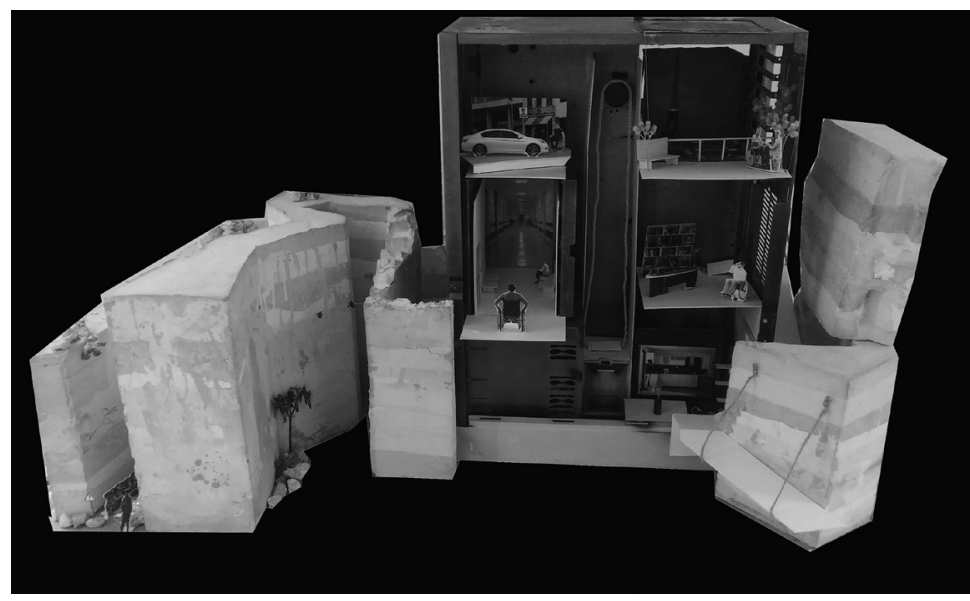

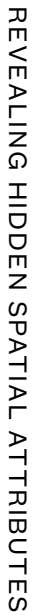

1: Constructing the narrative of the imaginary: Model
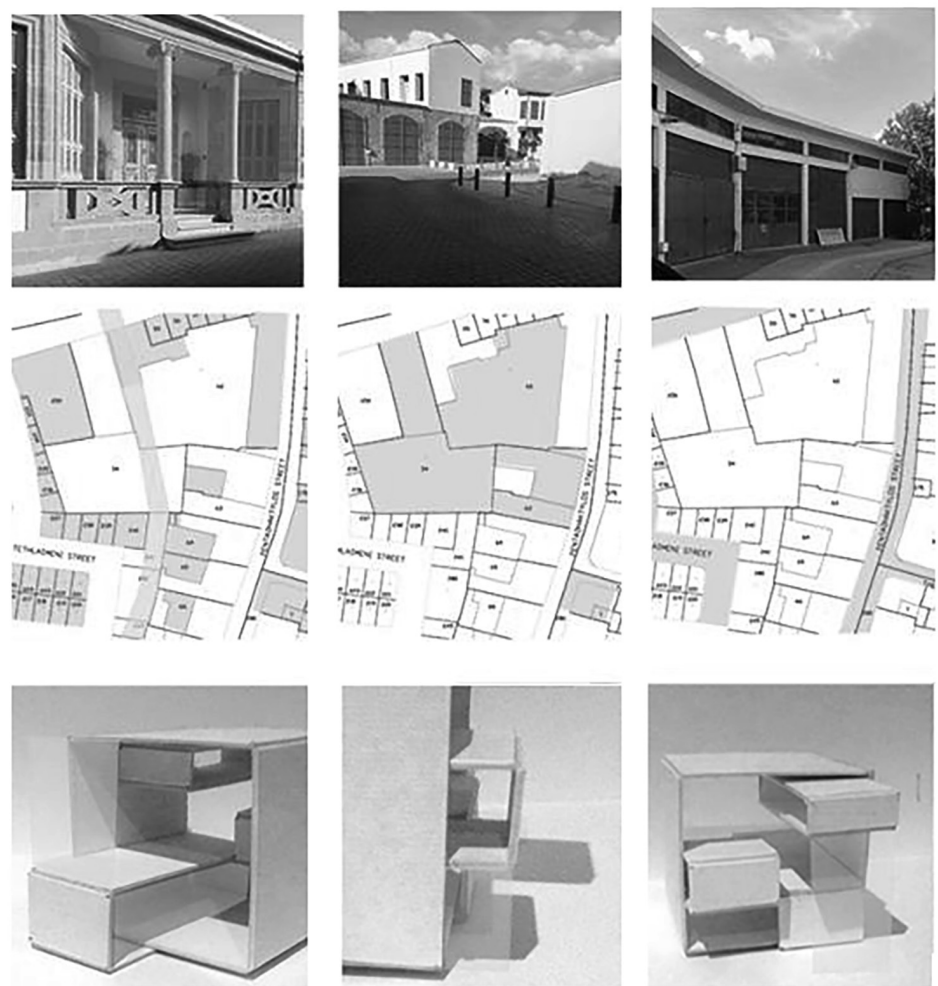

2: Hands-on Identifying, Mapping, Synthesizing_Urban Scale. 
年

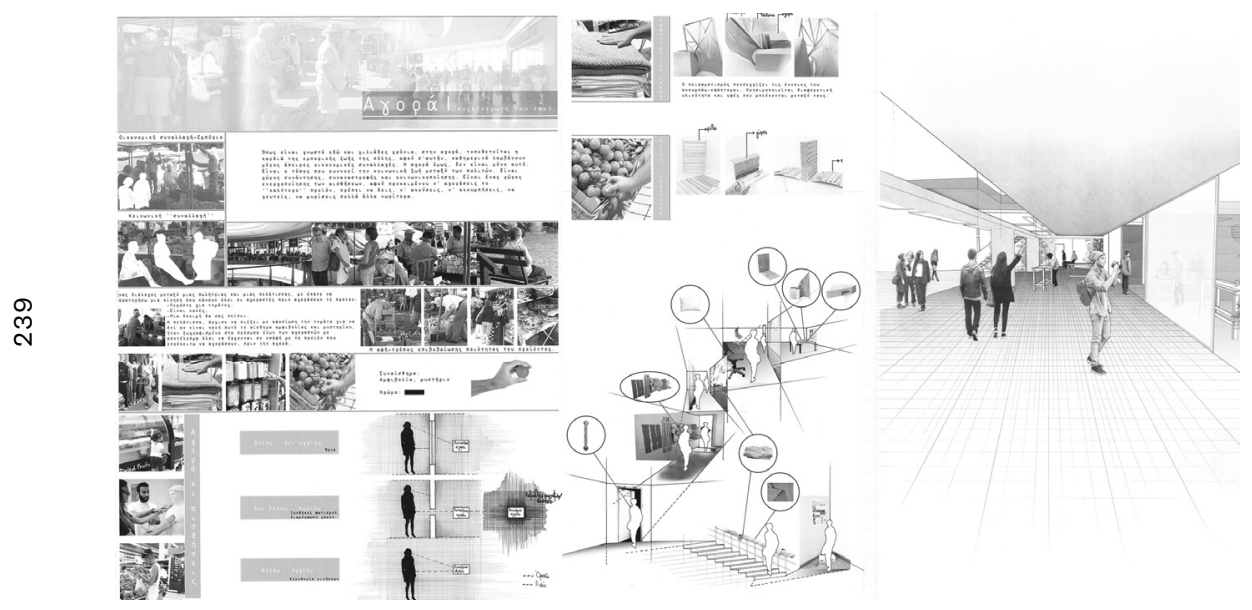

3: Social Encounters.

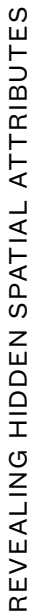

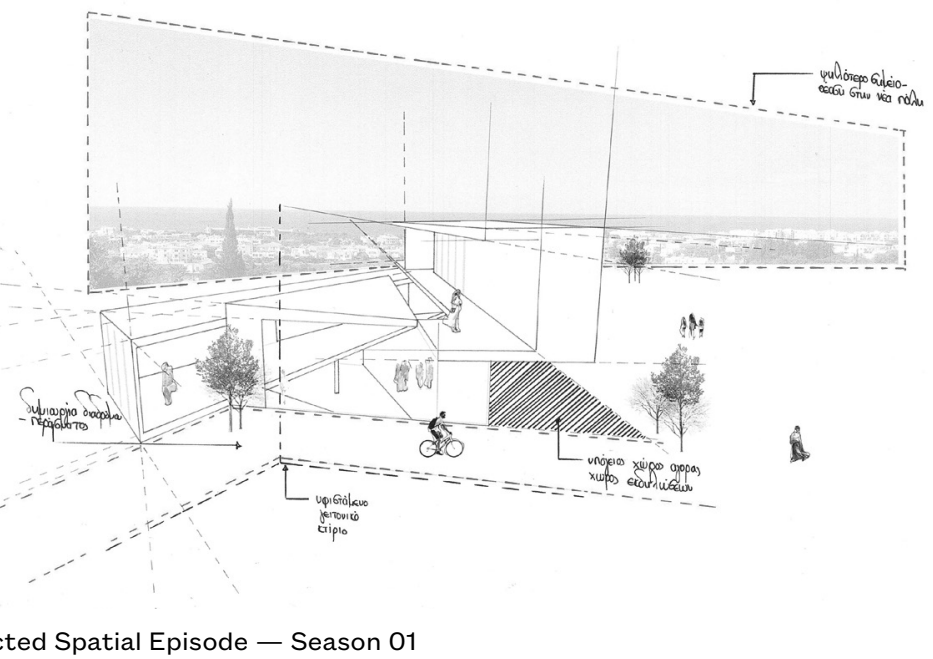

